\title{
A Razão Empreendedora na pesquisa em saúde
}

\author{
Entrepreneurial Logic in health research
}

Reinaldo Guimarães (https://orcid.org/0000-0002-0138-9594) ${ }^{1}$

\footnotetext{
${ }^{1}$ Núcleo de Bioética e Ética Aplicada, Universidade Federal do Rio de Janeiro. R. Venceslau Brás 71 , Botafogo. 22290-140 Rio de Janeiro RJ Brasil. reinaldo.guimarães47@ gmail.com
}

\begin{abstract}
The scope of this paper is a discussion of the transformative relationship between scientific research and productive innovation, which occurred from the final quarter of the twentieth century onwards. The main characteristic of the phenomenon was an intense space-time approximation of the two activities. The human health sector has been one of the main fields where that approximation was most markedly observed. Some major conceptual bases of the reorganization are discussed, and the text examines works by Gibbons, Stokes and Lundvall-Freeman, as well as Merton, Kuhn and Bourdieu with respect to the organization of the scientific work. The paper highlights and discusses three aspects that arose from the new configuration, namely the erosion of the well-established concept of scientific knowledge as a public good, the appearance of the individual referred to as the 'entrepreneurial researcher' and the emergence of the strategy of translational research in health.

Key words Scientific policy, Technological policy, Innovation, Applied ethics.
\end{abstract}

Resumo Discute-se a reorganização das relações entre a produção científica e as inovações produtivas a partir do quarto final do século XX cuja expressão mais geral foi uma intensa aproximação espaço-temporal entre essas duas atividades. O setor de saúde humana foi um dos setores onde essa aproximação ocorreu com grande intensidade e o texto discute algumas bases conceituais importantes nesse processo, trazendo as contribuições de Gibbons, Stokes e Lundvall-Freeman, bem como as de Merton, Kuhn e Bourdieu no que se refere à organização do trabalho científico. Aponta e discute três processos derivados dessa reorganização, quais sejam a erosão do conceito do conhecimento científico como um bem público, a difusão de um personagem denominado 'pesquisador empreendedor' e o aparecimento da estratégia da pesquisa translacional.

Palavras-chave Política científica, Política tecnológica, Inovação, Ética aplicada 
We have discovered the secret of life.

Francis Crick, em 1953, anunciando num pub londrino a descoberta da estrutura do DNA ${ }^{1}$.

Three billion bases of DNA sequence can be put on a single compact disc and one will be able to pull a CD out of one's pocket and say, 'Here is a human being; it's me!'. Walter Gilbert, geneticista, em 1993 quando do lançamento do Genoma Humano².

\section{Introdução: uma história exemplar}

Esses dois momentos, espaçados em 40 anos, sintetizam uma das vertentes do caminho percorrido pela biomedicina, que veio a se tornar o principal pilar da pesquisa em saúde humana na segunda metade do século XX. Ao expressar essa trajetória, os dois momentos expõem de modo concentrado o objetivo deste texto, que é o de analisar o desenvolvimento das relações entre a produção de conhecimento científico e a inovação produtiva no campo da saúde humana com vistas a discutir os desafios éticos postos pelo desenvolvimento dessas relações.

No pub, Crick (com James Watson) anunciava aos seus pares e provavelmente a alguns outros presentes uma descoberta científica que seria publicada integralmente logo depois na revista Nature. Para uma plateia eclética e seleta, Gilbert anunciava o lançamento de um produto tecnológico de base científica que, ao concretizar-se, revelou um custo de três bilhões de dólares, a maior parte oriunda de recursos públicos de vários países, principalmente dos Estados Unidos da América (EUA). A publicação de Watson e Crick, que lhes deu um Prêmio Nobel (junto com Maurice Wilkins), revolucionou a pesquisa biomédica, pode-se dizer inaugurando a biologia molecular. O Genoma Humano foi concluído em 2003 após uma corrida frenética entre um projeto público, financiado pelo National Institutes of Health (NIH) e um projeto privado, liderado por um 'pesquisador-empreendedor', Craig Venter, ex-pesquisador do NIH e acionista principal da empresa Celera Genomics. A primeira cerimônia para apresentação de resultados, entretanto, já havia acontecido em 2000 em cerimônia presidida pelo presidente Bill Clinton e com a participação remota do então $1^{\circ}$ ministro britânico Tony Blair, que não atribuíram um vencedor à corrida, simbolicamente impulsionando uma relação que se tornaria crescentemente canônica no finan- ciamento à pesquisa e à parceria entre as universidades e as empresas no campo da saúde. $\mathrm{O}$ governo dos EUA proibiu o patenteamento de sequências genômicas naturais, o que permitiu que pudessem ser livre e gratuitamente utilizadas por quaisquer pesquisadores. Essa decisão fez com que as ações da Celera sofressem grande queda e fossem, por fim, retiradas da bolsa. Estima-se que em dois dias tenha havido uma perda geral de 50 bilhões de dólares em ofertas de capitalização no setor empresarial de biotecnologia ${ }^{3}$.

\section{As relações contemporâneas entre produção de conhecimento e inovação produtiva. Por que saúde?}

Na segunda metade do século XX, em particular a partir da década de 1970, vêm ocorrendo dois processos associados. Por um lado, um incremento na importância do papel das inovações de base científica na dinâmica das economias industriais. Por outro, modificações profundas nas relações conceituais e práticas da pesquisa científica em relação às inovações tecnológicas em parte derivadas dela. Os dois processos tiveram origem no Hemisfério Norte, dos dois lados do Oceano Atlântico, após a 2a Guerra Mundial. Nos primeiros tempos, quase exclusivamente nos EUA, única potência relevante que saiu da guerra praticamente incólume seja em termos de sua base tecnológico-produtiva, seja em termos de massa crítica e capacidade instalada de pesquisa. Além disso, mediante a utilização sobre Hiroshima e Nagasaki de um artefato de base tecnológica avançada e derivado de pesquisa fundamental, tendo com isso anunciado claramente ao mundo que sua liderança científica e tecnológica passava a ser um componente central do seu poder político. Mais tarde, com a Europa reconstruída, seus principais países, com o concurso algo tardio da Alemanha, entraram também nesse amplo terreno da revisão das relações entre pesquisa fundamental e inovação produtiva. Um pouco mais tarde, o Japão incorporou-se a esse grupo de países. Ainda mais tarde a República da Coreia e, finalmente, a República Popular da China.

Muito embora essas relações transformadas tenham incidido sistemicamente em muitos setores industriais, elas tiveram particular impacto em dois deles, que são atualmente os mais dinâmicos em termos econômicos e tecnológicos. Em primeiro lugar, na indústria que utiliza tecnologias de informação e comunicação e em segundo lugar no setor industrial voltado à saúde humana. Segundo dados de 2017 para a União Euro- 
peia e os EUA, as despesas com pesquisa e desenvolvimento atingiram $€ 154,2$ bilhões no setor de informação e comunicação e $€ 103,9$ bilhões no setor industrial de saúde. O crescimento desses dispêndios entre 2007 e 2017 foram, respectivamente, de $64,4 \%$ e $70,0 \%{ }^{4}$.

O nosso objetivo neste texto é o de explorar as transformações na relação entre ciência e inovação produtiva no campo da saúde, no qual essas transformações são de grande monta e que, além disso, vem sendo objeto de intenso debate em torno da eticidade de sua atuação. Um dos trabalhos de maior impacto sobre esse tema foi lançado nos EUA em 2005, tendo alcançado impacto mundial ${ }^{5}$. Em seu componente industrial, este setor é altamente intensivo em tecnologia de base científica, muito oligopolizado e no que se refere ao seu componente mais importante em termos de valor de mercado - o segmento biofarmacêutico - muito concentrado em termos do número de componentes em cada um de seus produtos acabados. Essa última característica o diferencia da indústria de informação e comunicação, cujos produtos são muito menos verticalizados, incorporando centenas de componentes oriundos de muitos fornecedores, resultando em uma longa e complexa cadeia tecnológica e produtiva.

Em 1994, Michael Gibbons et al. propuseram uma nova forma de produção de conhecimento científico, que seria mais adequada à pesquisa no século XXI ${ }^{6}$. Talvez hiperbolicamente, o conceituaram como um novo "modo de produção", no qual adicionaram um aposto "tipo 2" contrapondo a ele um tradicional "modo de produção tipo 1", predominante em tempos anteriores. Esse novo "modo de produção" teria como características fundamentais: (1) Conhecimento produzido em um contexto de aplicação; (2) Transdisciplinaridade; (3) Diversidade e heterogeneidade institucionais; (4) Responsabilidade e reflexividade sociais; (5) Maior controle de qualidade. Em 2003, Gibbons e dois de seus colaboradores originais, voltaram ao tema sustentando seus pontos de vista e refutando críticas ao trabalho original ${ }^{7}$.

As características do "modo de produção" superado estariam em contraposição a essas características, a saber: um contexto de pesquisa básica apartado do ambiente de aplicação; um fundamento disciplinar; e um modelo institucional mais restrito, com grande predominância das universidades/institutos de pesquisa e pouca avaliação e responsabilização dos resultados, por parte de segmentos externos ao mundo da pesquisa. Efetivamente, o cenário sugerido por
Gibbons é facilmente observado em vários campos de produção de conhecimento, em particular naqueles que ordinariamente são chamados de áreas duras, muito embora ele procure estender a sua proposta às humanidades. Dentre os campos onde essa dinâmica é mais evidente, destacamse a pesquisa vinculada aos dois já mencionados setores tecnológico-industriais. Aquela, tendo a física como fundamento e uma grande variedade de subdivisões da engenharia como disciplinas contributivas, e essa tendo a biologia como fundamento e tendo a extensa família da genética, bioquímica, neurociência e das "ômicas" como disciplinas contributivas.

Dentre os cinco pontos apontados por Gibbons como característicos do novo "modo de produção", três deles parecem estar relacionados entre si. Os possíveis maiores controle de qualidade e reflexividade social estão provavelmente associados à expansão das modalidades institucionais nas quais a realização de pesquisa científica vem tendo lugar, em particular no campo das humanidades, mas também no campo da saúde (regulações éticas e sanitárias da pesquisa com seres humanos). O desenvolvimento de pesquisa de base científica em contextos de aplicação dificilmente pode ser considerado um atributo contemporâneo do fazer científico, conforme discutiremos em seções seguintes. E a interdisciplinaridade certamente é uma característica contemporânea que, a despeito disso, não parece suficiente para caracterizar um novo "modo de produção".

No âmbito institucional, além de novos tipos de organização (ONG’s, por exemplo), Gibbons apresenta o formato de redes de pesquisa (network) como a crescente forma padrão de colaboração científica e a contrapõe à antiga forma padrão - a equipe ou grupo de pesquisa, que remete ao velho "modo de produção", simbolizando arranjos mais rígidos e menos fluidos de trabalho científico. Como assinalam David et al. ${ }^{8}$ - que sugere contrapor o "novo" modo network ao antigo modo clockwork - no plano heurístico, essa metáfora contribui para caracterizar uma forma de colaboração cada vez mais presente no trabalho científico. Entretanto, se a metáfora for entendida como vetor de política científica, sugere um enfraquecimento das instituições tradicionais produtoras de conhecimento científico - universidades, institutos, etc. - que não se observa nos países líderes globais em pesquisa. Observe-se que o período de elaboração e lançamento do livro de Gibbons teve como pano de fundo ideológico as propostas de flexibilização e 
desregulamentação associadas às doutrinas neoliberais originadas na década anterior.

Outro pensador que, poucos anos após o trabalho de Gibbons, também tratou das formas de organização do trabalho científico e suas relações com a aplicação de seus resultados na vida econômica e social foi Donald Stokes. Publicado em 1997, seu livro intitulado "O Quadrante de Pasteur: A Ciência Básica e a Inovação Tecnológica" ${ }^{\prime \prime}$ faz a crítica do projeto de política científica e tecnológica que emergiu dos EUA após a $2^{\text {a }}$ Guerra Mundial, expresso em um documento assinado pelo assessor científico dos presidentes Roosevelt e Truman, intitulado Science, The Endless Frontier ${ }^{10}$. Seu autor, Vannevar Bush, fundamentava sua proposta de política científica e tecnológica para os EUA no pós-guerra em três conceitos básicos. São eles: (1) A ciência básica e suas aplicações são atividades independentes, no limite excludentes e, por vezes, opostas; (2) As inovações de base tecnológica ocorrem segundo uma sucessão linear de etapas que se iniciam na pesquisa básica, passam por pesquisa aplica$\mathrm{da}$, desenvolvimento de tecnologias chegando, a partir daí, às inovações; (3) As inovações de base tecnológica têm como fonte habitual a pesquisa científica. Diferentemente de Gibbons e em particular ao ponto 1 de sua proposta - a emergência da pesquisa em um contexto de aplicação - Stokes não anuncia um novo modo de fazer pesquisa surgido na segunda metade do século XX e sustenta que, historicamente, pelo menos desde a revolução científica do século XVII foi estabelecida uma relação de proximidade entre a pesquisa que objetivava a compreensão das leis naturais e as aplicações práticas a ela relacionadas. Mesmo reconhecendo um espaço próprio para a pesquisa básica, que denomina a "busca pelo entendimento fundamental", Stokes propõe a existência de um amplo espaço para uma pesquisa básica “inspirada por considerações de uso". Além disso, contempla a importante existência de inovações independentes de pesquisa científica. A partir dessas bases, sugere um modelo bidimensional no qual a partir do cruzamento da existência ou não do objetivo de entendimento fundamental com a existência ou não de consideração de aplicação, são gerados quadrantes, a saber: (1) o quadrante de Bohr, que inclui a pesquisa científica voltada exclusivamente ao avanço do conhecimento; (2) o quadrante de Pasteur, que inclui a pesquisa básica que, desde a sua concepção, contempla aplicações, e; (3) o quadrante de Edison, que inclui as inovações (aplicações) que se desenvolvem sem uma relação direta com pesquisa científica.
Os nomes conferidos aos quadrantes são bastante autoexplicativos, derivados da contribuição de cada um dos três homenageados ao desenvolvimento de novas ideias sem vinculação com inovações produtivas (Bohr), de produtos sem vínculos com novos conhecimentos científicos desenvolvidos especificamente para eles (Edison) e de inovações produtivas diretamente vinculadas a aquisições científicas fundamentais (Pasteur).

Em seu livro, Stokes está focado essencialmente no desenvolvimento político e institucional das políticas científica e tecnológica de seu país até o final dos anos 1990. Pela relativa identidade com o tema deste texto vale a pena destacar o relato do autor sobre o impacto na política de pesquisa dos EUA decorrente do lançamento do primeiro satélite artificial, o Sputnik, realizado pela União Soviética em 1957.

"Os Estados Unidos poderiam ter visto o Sputnik como um desafio a algum setor particular da tecnologia norte americana... Mas a comunidade de políticas [os políticos] também reagiu ao Sputnik como um desafio soviético geral à ciência norte americana... Como resultado, os anos que se seguiram a essa desagradável surpresa soviética foram anos de orçamentos crescentes para praticamente todos os ramos da ciência.... Do lançamento do Sputnik até a descida de um norte americano na Lua [1969], o apoio federal à ciência básica aumentou em termos reais por um fator de quase cinco"".

$\mathrm{O}$ interesse nesse fato decorre dele ter sido, numa escala gigantesca, uma reação governamental dirigida à comunidade científica para que esta respondesse a um desafio político no auge da Guerra Fria. Similarmente, embora em grau menor, entendo que a proposta da estratégia translacional na pesquisa em saúde, componente de política pública nas novas relações entre ciência e inovação, foi também um desafio governamental à comunidade científica norte-americana para responder a um problema, não mais político, mas econômico. Mais precisamente, responder às dificuldades da indústria farmacêutica transnacional ancorada nos EUA.

Tanto Gibbons quanto, em grau menor, Stokes enfrentam a questão do relacionamento entre ciência, tecnologia e inovação de um posto de observação predominantemente ligado à oferta de conhecimento. Mais especificamente, Stokes descreve e critica o processo de progresso técnico tal como era entendido no pós-guerra até a década de 1960. Um processo de desenvolvimento linear e unidimensional cujo sentido ia da descoberta científica à inovação produtiva. 
Como está hoje bem estabelecido, essa trajetória explicativa linear e baseada exclusivamente na oferta de conhecimento foi superada tanto como explicação teórica do progresso técnico quanto como modelo de organização de políticas nacionais de ciência, tecnologia e inovação produtiva em muitos países.

Quando as relações entre produção de conhecimento e inovações produtivas são analisadas predominantemente do ponto de vista da demanda, isto é, das inovações, a despeito de existir mais de uma abordagem explicativa, como por exemplo a importante abordagem da Triple $\mathrm{He}$ $l i x^{11}$, aquela que talvez seja a mais robusta e mais utilizada no terreno da economia da tecnologia e da inovação é a dos Sistemas Nacionais de Inovação. Ela nasceu na década de 1980 na Dinamarca (Bengt- Ake Lundvall) e foi posterior e especialmente desenvolvida na Universidade de Sussex (Reino Unido), no Science Policy Research Unit - SPRU, onde destaca-se o nome de Christopher Freeman. Em seguida, teve contribuições importantes nos Estados Unidos, na Itália e em outros países. De um modo sintético, essa abordagem interpretativa assenta-se sobre três fundamentos básicos. Em primeiro lugar, como o próprio nome sugere, sobre seu caráter nacional, a despeito do aumento das interações transnacionais decorrentes da globalização financeira e produtiva. Conforme Lundvall, os sistemas nacionais de inovação são constituídos por;

.. the elements and relationships which interact in the production, diffusion and use of new, and economically useful, knowledge ... are either located within or rooted inside the borders of a nation state $^{12}$.

O segundo fundamento diz respeito ao papel importante do Estado como organizador e muitas vezes ator executivo do sistema. O desenvolvimento da abordagem dos sistemas nacionais de inovação ocorreu a partir de uma matriz crítica às teorias econômicas neoclássicas e sob forte influência schumpeteriana. A partir desta matriz, ela recusa o papel do Estado como apenas um corregedor de "falhas de mercado", reservando a ele um papel muito maior e sistêmico na produção de inovação. Desenvolvimentos conceituais mais recentes vão ainda além, reconhecendo o avanço de uma interpretação sistêmica do Estado no processo de inovação, mas propondo uma função ainda maior do mesmo como principal investidor e formador do mercado em economias baseadas no conhecimento ${ }^{13}$.

O terceiro fundamento ressalta o caráter complexo, dinâmico e institucional do processo de inovação. Conforme Stan Metcalfe, os Sistemas Nacionais de Inovação compõem-se de grande variedade de instituições privadas e públicas:

.. that set of distinct institutions which jointly and individually contribute to the development and diffusion of new technologies and which provides the framework within which governments form and implement policies to influence the innovation process. As such it is a system of interconnected institutions to create, store and transfer the knowledge, skills and artefacts which define new technologies ${ }^{14}$.

Sumarizando as três visões explicativas do relacionamento entre o processo de produção de conhecimento e a inovação produtiva acima mencionados (Gibbons, Stokes e Lundvall/Freeman), destacam-se cinco aspectos que, a despeito de distintos pontos de observação, bases conceituais e alcances temporais cobertos por cada uma delas, podemos considerar serem importantes para os objetivos deste texto.

. A evidência de que o conhecimento tem um importante e crescente papel como fator de produção de riqueza, ao lado de fatores tradicionais como capital e trabalho.

- A dinâmica da transformação do conhecimento em novos produtos e processos é complexa, multi institucional e não linear.

- A base física da produção de conhecimento científico vem se expandindo, envolvendo, além das universidades e institutos de pesquisa, instituições não acadêmicas (organizações da sociedade civil) e empresas.

. A relação entre conhecimento de base científica e inovação produtiva vem dificultando, em termos espaciais e temporais, a discriminação entre os papéis e as práticas do pesquisador e do empreendedor/inovador.

- Por fim, em particular nas abordagens de Stokes e Lundvall/Freeman, que a unidade analítica mais importante no estudo desse relacionamento são os estados nacionais e que a presença do Estado nesse processo tem sido permanente, intensa e essencial.

Esses cinco pontos projetaram inúmeras repercussões tanto no campo da pesquisa científica quanto no da inovação produtiva, cujas análise e debate integrais escapam do escopo deste trabalho. Mas uma delas está no centro da hipótese que pretendemos explorar - os possíveis desafios éticos postos na prática da investigação científica no campo da saúde humana consequentes à dinâmica neles expressa. Na nossa compreensão, esses desafios éticos seriam derivados de três pro- 
cessos associados aos cinco pontos, resultados de sua evolução histórica, muito provavelmente não como consequência de um projeto racionalmente arquitetado, mas como uma sombra num terreno iluminado por esses novos relacionamentos, uma resultante objetivamente posta e que merece escrutínio e reflexão.

Os três processos são de natureza distinta; um deles teve origem no campo da economia - a erosão do tradicional e historicamente sancionado caráter de bem público do conhecimento científico; o segundo, situado predominantemente no campo sociológico - talvez não o aparecimento, mas a crescente disseminação de um personagem no fazer científico - o pesquisador-empreendedor - que expandiu-se para uma nova categoria institucional no qual o mesmo é protagonista, a universidade empreendedora; e o terceiro, localizado no campo da política pública - a estratégia translacional na pesquisa científica. Mas, a despeito das peculiaridades históricas e disciplinares entre os três, pensamos que é possível uma reflexão unitária sobre eles.

Essa reflexão unitária decorre do fato dos três processos estarem profundamente entrelaçados, sendo que a erosão do caráter público do conhecimento científico e a emergência do pesquisador empreendedor/universidade empreendedora são duas faces de uma mesma moeda incidentes em variados graus no conjunto das disciplinas científicas, inclusive nas ciências humanas e sociais. Nestas, as figuras dos economistas, sociólogos e cientistas políticos acadêmicos vinculados a bancos e a empresas de consultoria é uma ocorrência consagrada há bastante tempo. Igualmente importante é a adesão dessa modalidade de prática pelos pesquisadores nas ciências “duras”. Já a estratégia translacional é uma construção ideológica no campo da política pública específica para a pesquisa em saúde.

\section{A organização do trabalho científico - Aspectos conceituais}

Grande contribuição teórico-conceitual sobre a organização do trabalho científico foi originalmente desenvolvida nos EUA na primeira metade do século XX, a partir da epistemologia da ciência de Thomas Kuhn e da sociologia da ciência de Robert Merton. Em ambos a interpretação da organização do trabalho científico propõe que a ciência e os cientistas, a despeito de se conformarem no seio da sociedade e em permanente interação com ela, constituem-se num subconjunto especial da mesma com normas, práticas e um ethos próprios. Em Kuhn são ressaltados a organização da prática em comunidades de cientistas e o pilar conceitual que as conformam, sustentam e, em algum momento, as reconfiguram, estabelecido por ele como "Paradigmas"15. Em Merton", uma contribuição central é a formulação do que seria um ethos próprio do cientista e de sua comunidade, cujo abandono ou desvio macularia o fazer científico e que ele sintetizou em quatro atributos necessários: universalismo, desinteresse, ceticismo organizado e comunismo.

O universalismo é uma recusa, ou pelo menos um alerta contra o relativismo na ciência. Tomando aqui de empréstimo o conceito Kuhniano de paradigma, o universalismo propõe que dentro de um determinado paradigma, o fato científico deve buscar ser universal. O desinteresse propõe um vínculo indissolúvel e sobredeterminante entre o pesquisador, sua pesquisa e seus pares, independentemente de quaisquer outros interesses. O ceticismo organizado diz respeito à obrigação de manter acesa a tensão entre uma "verdade científica" aceita e a possibilidade de sua superação, no âmbito do paradigma (que Kuhn denomina de ciência normal) ou rompendo com ele e instituindo um novo. Finalmente, o comunismo preceitua a necessidade de compartilhamento e difusão máximas do conhecimento científico.

Salta aos olhos a distância que separa esses atributos mertonianos da prática científica no cenário atual. Ressalte-se, entretanto, que para Merton esses atributos seriam mais prescritivos do que descritivos, seriam mais o estabelecimento de um modelo capaz de propiciar a compreensão da produção do conhecimento científico do que uma descrição da prática dos cientistas em suas comunidades ${ }^{17}$.

Vale ainda comentar o fato de que uma mesma cultura em um mesmo Estado Nacional - os EUA - tanto gerou a estrutura interpretativa do processo de conhecimento científico moderno tal como proposto por Kuhn e principalmente por Merton, como foi também o território original da reorganização das relações entre ciência e inovação expressas nos três entrelaçados processos dela decorrentes, que colocaram em juízo as bases da reflexão daqueles dois autores. Para tentar interpretar as novas relações foi necessário o concurso de um olhar estrangeiro que, de resto, não esteve nem única nem centralmente interessado numa sociologia ou numa epistemologia da ciência e da inovação.

Em relação às proposições de Kuhn e Merton, uma visão radicalmente distinta do mundo da 
ciência e dos cientistas foi produzida na segunda metade do século XX por Pierre Bourdieu.

Para ele, a organização dos cientistas não se daria na forma de uma comunidade científica, mas num espaço muito mais amplo, denominado Campo, no qual, muito mais do que cooperação, é lugar de disputa. Bourdieu recusa a ideia de uma singularidade do mundo da ciência em relação ao que lhe é externo. Segundo ele, toda a estrutura social organiza-se por Campos, que são espaços de relações objetivas, com lógicas próprias, não reprodutíveis e irredutíveis à lógica que rege campos distintos. Os campos não são estruturas fixas, mas construções historicamente referidas. O que os organiza são interesses específicos, objeto da ação dos indivíduos e dos grupos nele contidos. Os campos produzem valores e são palco de lutas de poder, nos quais variadas formas de capital são negociados e reproduzidos. Entre essas formas, está a do capital simbólico ${ }^{18}$, especialmente importante no caso do campo científico, onde ele é objeto de disputa e também de potencial conversão em outras formas de capital - cultural, social e econômico ${ }^{19}$.

No campo científico, o principal móvel da competição pelo acúmulo de capital simbólico é a conquista da primazia (principal índice de crédito científico) das aquisições científicas e, como consequência, aumento do prestígio frente aos outros componentes do Campo.

"Mas, afinal, o que é crédito científico? É um capital simbólico, não monetário - leia-se autoridade/competência científica - uma espécie particular de capital 'que pode ser acumulado, transmitido e até reconvertido, sob certas condições, em outros tipos de capital' em um mercado específico, o da produção do conhecimento científico. Portanto, Bourdieu não faz apenas uma analogia do campo científico com o mercado capitalista, mas, indo além, propõe que esse é mais um mercado particular dentro da ordem econômica capitalista" ${ }^{20}$.

Para o nosso objetivo, importa centralmente compreender a dinâmica contemporânea e tendencial dos mecanismos de conversão potencial de capital simbólico em capital econômico, financeiro ou monetário empiricamente revelado pelo reordenamento das relações entre ciência e inovação produtiva. A visão de Bourdieu ao propor relações íntimas entre a ciência e o mercado não é consensual no âmbito dos estudiosos da sociologia e filosofia da ciência contemporâneos que, entre outras críticas, ressaltam um certo reducionismo do mundo da ciência e dos cientistas à determinantes econômicos. Não obstante, as novas formas de relacionamento entre a produção científica e a inovação produtiva, apresentados anteriormente, reforçam uma interpretação que aproxima ciência e mercado. Tanto por uma "descoberta" do mercado pela ciência, quanto por uma "descoberta" da ciência pelo mercado.

Apenas registro a existência de autores mais recentes no campo da sociologia e da epistemologia da ciência. Entretanto, penso que as abordagens etnográficas e micro sociológicas de Bruno Latour, Steve Woolgar e Karin Knorr-Cetina talvez dialoguem menos diretamente com o nosso objeto de discussão neste texto.

\section{O conhecimento científico como bem público}

Em 1942, ao definir o significado da categoria "comunismo", uma das quatro balizas que definiriam o ethos do trabalho científico, Robert Merton escreveu:

The substantive findings of science are a product of social collaboration and are assigned to the community. They constitute a common heritage in which the equity of the individual producer is severely limited. An eponymous law or theory does not enter into the exclusive possession of the discoverer and his heirs, nor do the mores bestow upon them special rights of use and disposition. Property rights in science are whittled down to a bare minimum by the rationale of the scientific ethic. The scientist's claim to 'his' intellectual 'property' is limited to that of recognition and esteem which, if the institution functions with a modicum of efficiency, is roughly commensurate with the significance of the increments brought to the common fund of knowledge ${ }^{16}$.

Essa conceituação sociológica do conhecimento científico como um bem público foi apropriada e traduzida pelos economistas mediante a aplicação de dois critérios. O primeiro é a não -excludabilidade (palavra não dicionarizada em português, mas presente na literatura econômica vinda do inglês excludability), que significa que ninguém pode ser impedido de consumir o bem. $\mathrm{O}$ segundo é a não-rivalidade, que significa que o consumo do bem por uma pessoa não impede (ou prejudica) o seu consumo por outra. Em outros termos, significa que o consumo por uma pessoa não extingue o bem. $O$ pertencimento ou não a esses dois critérios são posições polares, havendo hoje em dia várias situações intermediárias entre eles. A incidência de nuances entre esses dois critérios polares, que vêm caminhando quase sempre no sentido de uma erosão no con- 
ceito de bem público do conhecimento científico, foi determinado pelo aumento da relevância da descoberta científica nos processos de inovação produtiva e expressou-se pela presença cada vez maior de novos personagens e de modalidades no fazer científico. O primeiro deles foi a presença governamental como ator relevante na pesquisa, não apenas como financiador, mas interessado em seus resultados. $\mathrm{O}$ segundo foi a emergência de empresas também como atores importantes na realização de pesquisa científica in-house. E o terceiro foi o desenvolvimento de inúmeras formas de cooperação entre universidades/institutos de pesquisa e empresas, que evoluiu para a transformação de grupos de pesquisa acadêmica em empresas e, finalmente, para a própria redefinição da instituição universitária como uma "Universidade empreendedora" (Entrepreneurial University).

As relações entre a ciência e o interesse governamental percorreram caminhos muito diferentes na Europa e nos EUA. Neste último, a resistência de importantes segmentos sociais à presença do governo no apoio à ciência acompanhou a história do país até após a $1^{\text {a }}$ Guerra Mundial. Até aí, o espírito liberal e pragmático prevalente na sociedade privilegiou soluções para problemas práticos, oriundas do engenho de inventores. As universidades norte-americanas, ao longo do século XIX, apoiavam atividades de pesquisa científica, mas o apoio a estas era fundado nos mesmos moldes do modelo que foi predominante em sua constituição, isto é, de origem filantrópica. Na Europa, em particular na Alemanha e na França, a presença de um Estado central mais forte fez com que o apoio governamental às atividades de pesquisa tenha sido muito mais precoce. No caso alemão, com a separação entre as Escolas Técnicas de nível Superior para a formação técnica industrial e as universidades, responsáveis pelo desenvolvimento científico. No caso francês, o governo central teve grande influência na criação e organização, tanto das Grandes Écoles (formadora da elite política e científica) quanto das universidades (originalmente voltadas à formação profissional de nível superior).

Tanto na Europa quanto nos EUA, ao longo de todo o século XIX e na primeira metade do século $\mathrm{XX}$, a presença governamental mais relevante no apoio às atividades técnicas deu-se no apoio a necessidades militares ${ }^{21}$. A maior parte da estrutura governamental norte americana e europeia nessa modalidade de apoio desenvolveuse até as portas da $2^{\text {a }}$ Guerra Mundial. Ao final da mesma, as estruturas europeias estavam destruí- das e as norte-americanas, praticamente indenes, foram convertidas institucionalmente na máquina de fomento à pesquisa naquele país, ao lado de manterem o interesse em pesquisa voltada à defesa. O National Institutes of Health (NIH), foi transformado em agência de fomento à pesquisa em saúde em 1946 e a National Science Foundation agência de fomento às demais ciências foi fundada em 1950. Além dessas duas agências, os EUA possuem outros componentes que apoiam e realizam pesquisas. O valor total do orçamento de pesquisa sob a responsabilidade federal em 2018 foi, em números redondos e aproximados, US $\$ 160$ bilhões, sendo, grosso modo, 60\% destinados a pesquisa militar. No restante, cerca de metade pertence ao NIH e a outra metade às demais agências.

Para o nosso tema, fica evidente a importância dessa participação governamental como contratante, financiadora e executora de projetos de pesquisa científica na erosão do conhecimento científico como um bem público. Não apenas no campo militar, projetos científicos com participação governamental muitas vezes incluem cláusulas de sigilo decorrentes de motivos variados, a maior parte delas pelo contratante entender serem consideradas "estratégicas" certas conclusões ou achados, mesmo sem conotação militar ou mesmo simplesmente por terem o potencial de contrariar políticas governamentais em vários campos. No Brasil, alguns componentes organizacionais do Ministério da Saúde exigem cláusulas de sigilo em projetos por eles contratados e financiados. Normalmente, essas cláusulas expressam-se pela obrigação de ser obtida uma autorização prévia do contratante antes da divulgação de resultados da pesquisa. Outro exemplo vem do Instituto de Pesquisas Econômicas Aplicadas (IPEA), cujas normas de publicação de resultados de pesquisas lá produzidas obedecem a rigoroso processo de clearance realizado por um comitê institucional ${ }^{22}$.

O segundo personagem importante a ter presença crescente na produção de conhecimento científico foram empresas que, pela necessidade de proteger o conhecimento sobre as bases científicas incorporadas em seus produtos, decidiram verticalizar esse conhecimento criando grupos de pesquisa com relativa autonomia para conduzir projetos de pesquisa científica não diretamente vinculados às necessidades imediatas de seu $p i$ peline tecnológico. O exemplo talvez paradigmático desse processo de verticalização foi a precoce criação, na década de 1920, do Bell Labs. Vinculado originalmente a duas grandes empresas de 
telecomunicação (AT\&T e Western Telegraph), o laboratório foi responsável por importantes aquisições científicas no campo da rádio astronomia, dos fundamentos teóricos da computação, da elaboração do mapa em alta resolução do cosmos, do Laser, do efeito Hall-Quântico e da teoria da informação, entre outros. Em função dessas atividades, pesquisadores associados ao laboratório conquistaram nove prêmios $\mathrm{Nobel}^{23}$.

Além da criação de centros de pesquisa científica com o objetivo de proteger conhecimento, há exemplos de grandes empresas que estimularam atividades científicas internas com o objetivo de estabelecer pontes com pesquisadores em universidades e institutos de pesquisa. Estudo clássico nesse terreno foi publicado em 1992 por Gambardella, que demonstrou os efeitos positivos dessa estratégia em um conjunto de empresas farmacêuticas norte americanas. $\mathrm{O}$ autor demonstra que as empresas que apostaram na criação de grupos de cientistas básicos in-house tiveram maior sucesso no lançamento de novos produtos no mercado ${ }^{24}$.

Novas estratégias negociais desenvolvidas neste século enfraqueceram essa modalidade de organização in-house de pesquisa científica em empresas, em particular nos setores industriais mais dinâmicos e mais intensos em tecnologias. Tanto no complexo da saúde quanto no complexo eletrônico, por razões variadas, observa-se um intenso processo de desverticalização e terceirização tecnológica e produtiva ${ }^{25,26}$. De qualquer modo, parece-nos importante fazer o registro da verticalização com incorporação de pesquisa científica em empresas com vistas à nossa discussão das restrições ao caráter de bem público do conhecimento científico.

$\mathrm{O}$ mecanismo mais disseminado para retirar do conhecimento científico seu caráter de bem público é o de abrigá-lo em uma das proteções legais existentes, sendo a mais importante delas o patenteamento com vistas a posterior eventual licenciamento a empresas. A apropriação privada de ideias, formalizadas sob a forma de invenções, originou-se no século XV, em Veneza e em Florença e, a partir daí, sofreu uma série de desenvolvimentos, consolidados em nível internacional apenas em 1883 na Convenção de Paris. Entretanto, o tema das patentes passou a ser um item relevante de política pública apenas quando, ao longo do século XX, a atividade inventiva foi se deslocando crescentemente de indivíduos para instituições voltadas para esse fim e seus atores passaram de inventores a cientistas. $\mathrm{O}$ epítome desse interesse dos governos com o tema deu-se em 1994 com a assinatura do acordo TRIPS (Trade-Related Intellectual Property Rights), que vinculava o ingresso de um país à então recém-criada Organização Mundial do Comércio à assinatura do acordo. $\mathrm{O}$ TRIPS representou uma harmonização de regras e abriu caminho a uma radicalização do regime internacional de patentes segundo os interesses dos países líderes industriais detentores da imensa maioria das patentes depositadas no mundo - EUA, Alemanha, Reino Unido, França, Japão e, mais recentemente, Coreia e China.

A iniciativa legal pioneira que estendeu o regime de patentes para o ambiente científico e acadêmico ocorreu nos Estados Unidos em 1980 e recebeu o nome dos dois senadores que o propuseram ao senado norte-americanos - Lei Bayh-Dole. Em linhas gerais, essa Lei permite o patenteamento institucional de invenções ocorridas em universidades, pequenas empresas e organizações sem fins lucrativos por essas instituições. A repartição dos benefícios financeiros potenciais entre a universidade e o pesquisador responsável pela pesquisa dá-se segundo normas de cada instituição. A Lei se aplica apenas às invenções cuja pesquisa tenha sido financiada no todo ou em parte por uma agência federal. A instituição detentora da patente tem a obrigação de conceder um licenciamento voluntário e não exclusivo ao governo federal que tem o poder de cancelar a patente no caso de invenções vinculadas à segurança nacional. A instituição detentora da patente obriga-se a utilizar os recursos financeiros oriundos da exploração comercial da patente por terceiros em despesas com pesquisa ${ }^{27}$. O sentido geral da Lei Bayh-Dole foi replicado em outros países detentores de massa crítica e produção industrial relevantes, inclusive o Brasil, onde inspirou a Lei de Inovação promulgada em 2004 e o Marco Legal de Ciência, Tecnologia e Inovação, de 2018.

O aumento da intensidade da cooperação entre as instituições acadêmicas e empresas e a transformação de grupos de pesquisa em pequenas empresas cujo destino é ser adquirida por ou fundida a uma empresa de maior porte são, atualmente, os processos mais importantes a contribuir para a erosão e complexificação do conhecimento científico como um bem público. Em audiência pública convocada pela Câmara dos Deputados dos EUA em 2012, foi relatado um resumo da performance das relações universidade-empresa naquele país.

In the decades leading up to the 1980 BayhDole Act, the Federal Government accumulated title to approximately 28,000 patents, of which 
fewer than five percent were licensed to companies for commercialization.... Since the Bayh-Dole Act was passed, more than 5,000 new companies have formed around university research, the majority of which are located in close proximity to the university. In fiscal year 2010, university research helped create on average 1.7 new companies a day. University technology transfer creates billions of dollars of direct benefits to the U.S. economy every year ${ }^{28}$.

Em artigo mais recente, foram analisadas 164.378 patentes concedidas pelo escritório nacional de patentes dos EUA (USPTO) entre 1980 e 2007 e nestas foram identificadas 30.829 que estavam diretamente vinculadas a apoios financeiros concedidos pelo NIH, sendo que a maioria desses apoios foi destinado a universidades, hospitais e institutos de pesquisa. Dessas, 17.093 patentes estavam relacionadas a aplicação dos dispositivos da Lei Bayh-Dole ${ }^{29}$.

A distância entre as propostas mertonianas sobre o caráter público do conhecimento científico e os mecanismos atuais de apropriação desse conhecimento é muito grande e a polaridade simples colocada pelos conceitos de não rivalidade e não excludabilidade tornou-se bem mais complexa.

\section{Agradecimentos}

O autor agradece a leitura cuidadosa do manuscrito e sugestões realizadas pela Dra. Marcia Oliveira Teixeira. Entretanto, o conteúdo publicado é de responsabilidade exclusiva do autor. 


\section{Referências}

1. Markel H. The Day Scientists Discovered the 'Secret of Life'. PBS New Hour. 2013. [acessado 2018 Ago 20]. Disponível em: https://www.pbs.org/newshour/ health/the-pub-where-the-secret-of-life-was-firstannounced

2. Rose H, Rose S. Genes, Cells and Brains: the Promethean promises of the new biology. London: Verso Books; 2012.

3. Wikipedia. Human Genome Project. [acessado 2018 Jan 15]. Disponível em: https://en.wikipedia.org/ wiki/Human_Genome_Project

4. The 2017 EU Industrial R\&D Investment Scoreboard. [acessado 2018 Nov 30]. Disponível em: https://www. Iri.jrc.ec.europa.eu/scoreboard $17 / \mathrm{html}$

5. Angell M. A Verdade Sobre Os Laboratórios Farmacêuticos. Rio de Janeiro, São Paulo: Editora Record; 2007.

6. Gibbons M, Limoges L, Nowotny H, Schwartzman S, Scott P, Trow M. The New Production Of Knowledge: The Dynamics of Science and Research in Contemporary Societies. London: Sage Publications; 1994.

7. Nowotny H, Scott P, Gibbons M. Introduction: 'Mode 2' Revisited: The New Production of Knowledge. Minerva 2003; 41(3):179-194.

8. David P, Foray D, Steinmueller WE. The Research Network and the New Economics of Science: From Metaphors to Organizational Behaviours. In: Gambardella A, Malerba F. The Organization of Innovative Activities in Europe. Cambridge: University Press; 1998. p. 128.

9. Stokes DE. O Quadrante de Pasteur: a ciência básica e a inovação tecnológica. Campinas: Editora da UNICAMP; 2005.

10. Bush V. Science The Endless Frontier. A Report to the President by Vannevar Bush, Director of the Office of Scientific Research and Development, July 1945. [acessado 2018 Out 15]. Disponível em: https://www. nsf.gov/od/lpa/nsf50/vbush1945.htm

11. Etzkowitz H, Leydesdorff L. The Triple Helix-University-Industry-Government Relations: A Laboratory For Knowledge Based Economic Development. EASST Review 1995; 14(1):14-19. [acessado 2018 Out 13]. Disponível em: https://www.leydesdorff.net/ th12/th12.pdf

12. Freeman C. The 'National System of Innovation' in historical perspective. Cambridge Journal of Economics 1995; 19(1):5-24.

13. Mazzucato M. O Estado empreendedor: desmascarando o mito do setor público vs setor privado. São Paulo: Portfolio-Penguin; 2014.

14. Metcalfe S. The Economic Foundations of Technology Policy: Equilibrium and Evolutionary Perspectives. In: Stoneman P, editor. Handbook of the Economics of Innovation and Technological Change. Oxford, Cambridge: Blackwell Publishers; 1995. p. 409-512.

15. Kuhn TS. A estrutura das revoluções científicas. $9^{\mathrm{a}} \mathrm{ed}$ São Paulo: Perspectiva; 2006.

16. Merton RK. The Normative Structure of Science. 1942. [acessado 2018 Ago 20]. Disponível em: https://www. panarchy.org/merton/science.html
17. Lima NT. Valores sociais e atividade científica: um retorno à agenda de Robert Merton. In: Portocarrero V, organizador. Filosofia, história e sociologia das ciências I: abordagens contemporâneas [online]. Rio de Janeiro: Editora Fiocruz; 1994. p. 166-167.

18. Bourdieu P. Capital Symbolique Et Classes Sociales Pierre Bourdieu. L'Arc 1978; 72:1-9.

19. Thiry-Cherques HR. Pierre Bourdieu: a teoria na prática. Revista de Administração Pública 2006; 40(1):27-55.

20. Hochman G. A ciência entre a comunidade e o mercado: leituras de Kuhn, Bourdieu, Latour e Knorr-Cetina. In: Portocarrero V, organizador. Filosofia, história e sociologia das ciências I: abordagens contemporâneas. Rio de Janeiro: Editora Fiocruz; 1994. p. 199-231.

21. Brooks H. National Science Policy and Technological Innovation. [acessado 2018 Out 28]. Disponível em: ftp://ftp.ige.unicamp.br/pub/CT010/aula\%204/ Brooks(1986).pdf

22. Instituto De Pesquisa Econômica Aplicada (IPEA). Instrução Normativa 2008. Determina Critérios Para A Produção Editorial Do IPEA. [acessado em 04/12/2018]. Disponível em: http://www.ipea. gov.br/acessoainformacao/dados/diretoriacolegiada/2008/2008.06.24/Documentos/24062008-8.pdf

23. Wikipedia. Bell Labs. [acessado 2018 Dez 13]. Disponível em: https://en.wikipedia.org/wiki/Bell_Labs

24. Gambardella, A. Competitive advantages from inhouse scientific research: The US pharmaceutical industry in the 1980s. Research Policy 1992; 21:391-407. [acessado 2018 Dez 13]. Disponível em: http://sjbae. pbworks.com/w/file/fetch/93336408/Gambardella\%20(1992).\%20Competitive $\% 20$ advantages $\% 20$ from\%20in-house $\% 20$ scientific\%20research.\%20RP. pdf

25. Lima RRL. Complexo eletrônico: a evolução recente e os desafios para o setor e para a atuação do BNDES. [acessado 2018 Out 4]. Disponível em: https://web. bndes.gov.br/bib/jspui/bitstream/1408/937/1/Complexo\%20Eletronico_\%20a\%20evolucao\%20recente_final.pdf

26. Silva FR. Desverticalização Das Cadeias Produtivas No Setor De Produção De Biomedicamentos E A Utilização Das Empresas CMOS (Contract Manufacturing Organization) [tese]. Rio de Janeiro: COPPE; 2016.

27. Cruz HN, Souza RF. Sistema Nacional de Inovação e a Lei da Inovação: Análise Comparativa Entre o BayhDole Act e a Lei da Inovação Tecnológica. Revista de Administração e Inovação 2014; 11(4):329-354.

28. United States of America. The Subcommittee On Technology And Innovation Committee On Science, Space, And Technology House Of Representatives. Best Practices In Transforming Research Into Innovation: Creative Approaches To The Bayh-Dole Act. The Subcommittee On Technology And Innovation Committee On Science, Space, And Technology House Of Representatives; Tuesday, June 19, 2012. The Association Of University Technology Managers. [acessado 2019 Jan 12]. Disponível em: https://www.govinfo. gov/content/pkg/CHRG-112hhrg74722/pdf/CHRG112hhrg74722.pdf 
29. Li D, Azoulay P, Sampat BN. The Applied Value of Public Investments in Biomedical Research. Science 2017; 356(6333):78-81. [acessado 2019 Jan 12]. Disponível em: https://dspace.mit.edu/openaccess-disseminate/1721.1/111116

Artigo apresentado em 11/04/2019

Aprovado em 20/05/2019

Versão final apresentada em 22/05/2019 